\title{
Impact of Doctor Role Models on Professional Development of Medical Students
}

\author{
Maria Khan ${ }^{1}$, Brekhna Jamil ${ }^{2}$ and Fatima Muhammad ${ }^{3}$ \\ ${ }^{1}$ Department of Pathology, Rehman Medical Institute, Peshawar, Pakistan \\ ${ }^{2}$ Institute of Health Professions Education, Khyber Medical University, Peshawar, Pakistan \\ ${ }^{3}$ Department of Medical Education, Northwest School of Medicine, Peshawar, Pakistan
}

Role modelling is an impactful and dynamic form of teaching and learning as well as one of the constituents of medical education. However, as a process, it goes mostly unnoticed. Even though role modelling can be traced back to olden times, but it has not been recognised in medical curriculum throughout Pakistan. Positive role models have a substantial bearing on the transfer of education and delivery of training by building a favourable culture for learning. Literature revealed the clinical brilliance, humanistic personality and teaching quality, as the three vital features of role modelling. Moreover, fundamental objectives of role modelling in medical field are competence in clinical skills, teaching qualities, and professionalism or personal qualities as well as choice of career pathways. Teaching medical education, by example, was an approach based largely on role modelling that is thought to be a fundamental factor in shaping the attitudes, values, behaviour, and ethics of medical students. ${ }^{1}$ In Pakistan, medical institutions had customarily traditional curricula, ceremonial and hierarchy associations between tutors and students, and clinical training programmes are aligned to acquire technical skills and medical knowledge only. ${ }^{2}$ In the present medical education, workplace-based learning, and the effects of social and cultural values on professional development forms an integral component of the curriculum as well as a choice of role models. ${ }^{3}$

Role models are defined as "individuals admired by their ways of being and acting as professionals". ${ }^{4}$ Furthermore, role modelling in medical literature are distinct from mentors as they inspire and demonstrate exclusively by example; whereas, mentors have an official affiliation with students. ${ }^{5}$ According to Mutter and Pawlowski,"Role model is an individual perceived as exemplary or worthy of imitation." ${ }^{6}$ In other words, a person who is respected, followed, copied, and "one who provides a code of behaviour and a set of values to be emulated." ${ }^{7}$

Correspondence to: Dr. Maria Khan, Department of Pathology, Rehman Medical Institute, Peshawar, Pakistan E-mail: kmaria22@hotmail.com

Received: April 07, 2021; Revised: April 28, 2021; Accepted: April 28, 2021

DOI: https://doi.org/10.29271/jcpsp.2021.05.495
Moreover, role modelling is a practice that includes conscious and subconscious components and comprises of an exposure phase followed by an evolution phase, then judgment phase and finally model training phase, during which decision to trial is reached. ${ }^{8}$ Irby referred role modelling as a course in which "faculty members demonstrate clinical skills, model and articulate expert thought processes and manifest positive professional characteristics." ${ }^{\prime 9}$ Role modelling in medical education is a paradox, at the same time it is an significant element of two broadly esteemed learning theories, Bandura's social learning theory ${ }^{10}$ and cognitive apprenticeship. ${ }^{11}$ People learn through observing, imitating, and modelling. ${ }^{10}$ In Pakistan, there is little knowledge regarding the practice; whereby, doctor role modelling takes place, and what is exercised is often subliminal with the influence going on more, by example, rather than directaction.

Clearly, role modelling has been defined as vehementeducational stratagem, specifically opting to apprenticeship scheme of training in medicine happening throughout educational environments, i.e. during the course of informal, formal and hidden curriculum, as well as undergraduate and postgraduate medical education. ${ }^{9}$ At the same time, it shapes the practice values, and professionalism and influences the students' conduct towards delivery of healthcare facilities. Basically, students' professional identity forms by means of perceiving their trainers interconnect with colleagues, patients and others. ${ }^{12}$ During the clinical training, medical students' learning, attitudes, behaviours, ethics and professional capabilities develops by observing their instructors' practicing medicine not just during formal, but informal settings as well. ${ }^{13}$

Generally, attributes recognised and most highly ranked by students in positive role models are related to clinical skills, conversely, in negative role models inadequate humanistic and poor collaborative attitudes are commonly observed. ${ }^{14}$ Additionally, individual quirks, clinical competence, teaching abilities and professionalism, respectively, were considered integral elements. ${ }^{15}$ Similarly, role models aspects were categorised among personal qualities, patient-care qualities and teaching qualities. ${ }^{16}$ According to Wright et al., the determinants for choosing a role model are competence, personality, clinical skills and teaching aptitude, while research accomplishments and academic rank were of lowest significance. ${ }^{17} \mathrm{~A}$ number of occidental countries also revealed humanistic attitude and collaborative skills as minimum gages for choosing a doctor as role model. ${ }^{18}$ 
In short, clinical teachers made good role models provided they possess complete clinical reasoning, outstanding judgment aptitude, sound patientmanagementand diagnosticexpertise, undertake clinical rounds proficiently, compliant, and hold the ability to achieve all facets of clinical management. ${ }^{15}$

In contrast, negative modelling was frequently highlighted in the literature as students often recalled negative traits rather than positive role modelling. ${ }^{19}$ Equally, negative role models render strong influence on students' outlooks and professional activities. However, negative role models can be a part of medical education that can help pupils what behaviours and attitudes ought to be avoided in their prospective practice that take account of lack of collegiality, esteem, and empathy towards patients. ${ }^{14}$ Alternatively, Murakami et al. specified the antagonistic effects of negative role models on career choices and professional behaviour. ${ }^{20}$ Therefore, teachers should at all times be cognizant and appreciate their collaborations, individual views, conducts and outlooks that are monitored by students in multiple scenarios. A Lebanese medical school studied the perception of clinical teachers as role models, which revealed only $38 \%$ of the study group being influenced by their role models while deciding specialty of choice. $^{14}$

In conclusion, throughout the literature of the medical education on the doctor/clinical teacher as a role model for students (undergraduates, residents and interns), wide-ranging lists of attributes were identified that described positive rolemodels as well as negative role models that are distributed among three categories namely, patient-care qualities/clinical skills, teaching qualities, and personal qualities. This paper highlights role modelling as an imperative aspect for the professional growth of doctors. Therefore, positive role models not only aid in modelling the professional development of our future doctors, but also serves an inspiration towards career choices. However, the negative impact of role models who fail to achieve adequate professional standards can, in the same way, be effective; and teachers need to contemplate methods to reduce this influence. In order to improve role modeling and avoid transmission of negative behaviour, awareness at training level of medical specialists and explicit incorporation in medical curricula is mandatory.

\section{REFERENCES}

1. Wright SM, Kern DE, Kolodner K, Howard DM, Brancati FL. Attributes of excellent attending-physician role models. New England J Medicine 1998; 339(27):1986-93. doi: 10.1056/ NEJM199812313392706.

2. Nasim M. Medical education needs to change in Pakistan. J Pak Med Assoc 2011; 61(8):808-11.

3. Billett S. Learning through health care work: Premises, contributions and practices. Medical Education 2016; 50(1): 124-31. doi: 10.1111/medu.12848.

4. Côté L, Leclère $H$. How clinical teachers perceive the doctorpatient relationship and themselves as role models. Academic Medicine 2000; 75(11):1117-24. doi: 10.1097/
00001888-200011000-00020.

5. Ricer RE. Defining preceptor, mentor, and role model. Family Med 1998; 30(5):328.

6. Mutter F, Pawlowski T. Role models in sports-Can success in professional sports increase the demand for amateur sport participation? Sport Management Review 2014; 17(3): 324-36. doi.org/10.1016/j.smr.2013.07.003.

7. Gladding ST, Villalba J. Imitation, impersonation, and transformation: Using male role models in films to promote maturity. J Counseling Development 2014; 92(1):114-21. doi.org/10.1002/j.1556-6676.2014.00137.x.

8. Passi $\mathrm{V}$, Johnson $\mathrm{N}$. The hidden process of positive doctor role modelling. Med Teach 2016; 38(7):700-7. doi: 10.3109/ 0142159X.2015.1087482.

9. Irby DM: Clinical teaching and the clinical teacher. J Med Educ 1986; 61(2):35-45.

10. Bandura A, McClelland DC. Social learning theory. Prentice Hall: Englewood cliffs; 1977 Oct.

11. Brown JS, Collins A, Duguid P. Situated cognition and the culture of learning. Educat Res 1989; 18(1):32-42.

12. Park J, Woodrow SI, Reznick RK, Beales J, MacRae HM. Observation, reflection, and reinforcement: surgery faculty members' and residents' perceptions of how they learned professionalism. Acad Med 2010; 85(1):134-9. doi: 10.1097/ACM.0b013e3181c47b25.

13. Yousuf R, Salam A. Role modeling in clinical educators: An important issue in medical education. South East Asia J Public Health 2015; 5(1):49-50.

14. Yazigi A, Nasr M, Sleilaty G, Nemr E. Clinical teachers as role models: Perceptions of interns and residents in a Lebanese medical school. Medical Education 2006; 40(7):654-61. doi: 10.1111/j.1365-2929.2006.02502.x.

15. Bazrafkan L, Hayat AA, Tabei SZ, Amirsalari L. Clinical teachers as positive and negative role models: an explanatory sequential mixed method design. J Med Ethics Hist 2019; 12: 11. doi: 10.18502/jmehm.v12i11.1448.

16. Jochemsen-van der Leeuw HR, van Dijk N, van EttenJamaludin FS, Wieringa-de Waard M. The attributes of the clinical trainer as a role model: A systematic review. Academic Medicine 2013; 88(1):26-34. doi: 10.1097/ ACM.0b013e318276d070.

17. Wright S, Wong A, Newill C. The impact of role models on medical students. J Gen Intern Med 1997; 12(1):53-6. doi: 10.1046/j.1525-1497.1997.12109.x.

18. Maheux B, Beaudoin C, Berkson L, Côté L, Des Marchais J, Jean P. Medical faculty as humanistic physicians and teachers: The perceptions of students at innovative and traditional medical schools. Medical Educ 2000; 34(8): 630-4. doi: 10.1046/j.1365-2923.2000.00543.x.

19. Cruess SR, Cruess RL, Steinert Y. Role modelling-making the most of a powerful teaching strategy. BMJ 2008; 336(7646): 718-21. doi: 10.1136/bmj.39503.757847.BE.

20. Murakami M, Kawabata H, Maezawa M. The perception of the hidden curriculum on medical education: an exploratory study. Asia Pacific Family Medicine 2009; 8(1):1-7. doi: 10.1186/1447-056X-8-9. 